\title{
The rapid transformation of cardiac surgery practice in the coronavirus disease 2019 (COVID-19) pandemic: Insights and clinical strategies from a center at the epicenter
}

Isaac George, MD, Michael Salna, MD, Serge Kobsa, MD, PhD, Scott Deroo, MD, Jacob Kriegel, MD, David Blitzer, MD, Nicholas J. Shea, MD, MS, Alex D'Angelo, MD, Tasnim Raza, MD, Paul Kurlansky, MD, Koji Takeda, MD, PhD, Hiroo Takayama, MD, PhD, Vinayak Bapat, MD, Yoshifumi Naka, MD, PhD, Craig R. Smith, MD, Emile Bacha, MD, and Michael Argenziano, MD

\section{ABSTRACT}

Background: The onset of the coronavirus disease 2019 (COVID-19) pandemic has forced our cardiac surgery program and hospital to enact drastic measures that has forced us to change how we care for cardiac surgery patients, assist with COVID-19 care, and enable support for the hospital in terms of physical resources, providers, and resident training.

Methods: In this review, we review the cardiovascular manifestations of COVID-19 and describe our system-wide adaptations to the pandemic, including the use of telemedicine, how a severe reduction in operative volume affected our program, the process of redeployment of staff, repurposing of residents into specific task teams, the creation of operation room intensive care units, and the challenges that we faced in this process.

Results: We offer a revised set of definitions of surgical priority during this pandemic and how this was applied to our system, followed by specific considerations in coronary/valve, aortic, heart failure and transplant surgery. Finally, we outline a path forward for cardiac surgery for the near future.

Conclusions: We recognize that individual programs around the world will eventually face COVID-19 with varying levels of infection burden and different resources, and we hope this document can assist programs to plan for the future. ( $\mathrm{J}$ Thorac Cardiovasc Surg 2020;160:937-47)

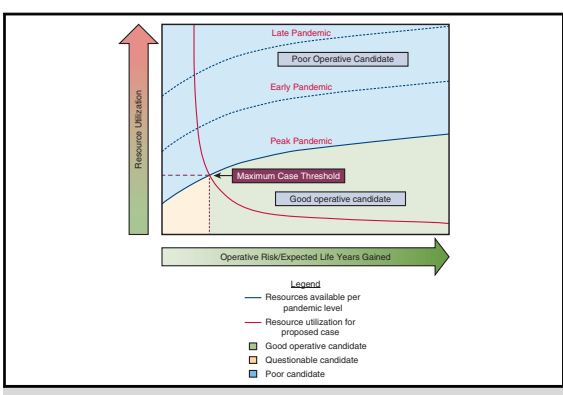

Decision-making strategy for cardiac surgery patients in the COVID-19 pandemic.

\section{CENTRAL MESSAGE}

The COVID-19 pandemic has

forced significant changes in car-

diac surgery, such as reorganizing staff, repurposing hospital space, redefining surgical priority, and changing clinical practice.

\begin{abstract}
PERSPECTIVE
Coronavirus disease 2019 (COVID-19), caused by the severe acute respiratory syndrome coronavirus-2 (SARS-CoV-2), has become a global pandemic that has overwhelmed entire health care systems. Our cardiac surgery center in New York City, NY, faced sudden challenges after a rapid influx of patients with COVID-19 in early March 2020.
\end{abstract}

See Commentaries on pages $948,949,951$, and 952.

\footnotetext{
From the Division of Cardiac, Thoracic, and Vascular Surgery, NewYork Presbyterian Hospital/Columbia University Irving Medical Center, New York, NY.

Drs George and Salna contributed equally to this manuscript.

This article has been copublished in The Journal of Thoracic and Cardiovascular Surgery, The Annals of Thoracic Surgery, and the European Journal of CardioThoracic Surgery.

Received for publication April 14, 2020; revisions received April 14, 2020; accepted for publication April 18, 2020; available ahead of print July 2, 2020.
}

\footnotetext{
Address for reprints: Isaac George, MD, Division of Cardiothoracic Surgery, NewYork Presbyterian Hospital-Columbia University Irving Medical Center, College of Physicians and Surgeons of Columbia University, MHB 7GN-435, 177 Fort Washington Ave, New York, NY 10032 (E-mail: ig2006@cumc.columbia.edu). $0022-5223 / \$ 36.00$

Copyright (C) 2020 Jointly between The American Association for Thoracic Surgery, The Society of Thoracic Surgeons, and the European Association for Cardio-Thoracic Surgery. Published by Elsevier Inc. https://doi.org/10.1016/j.jtcvs.2020.04.060
} 


\section{Abbreviations and Acronyms \\ COVID-19 = coronavirus disease 2019 \\ $\mathrm{ECMO}=$ extracorporeal membrane oxygenation \\ ICU = intensive care unit \\ LVAD $=$ left ventricular assist device \\ OR $=$ operating room \\ ORICU = operating room intensive care unit \\ PPE $=$ personal protective equipment \\ SARS-CoV $=$ severe acute respiratory syndrome coronavirus \\ STS $=$ Society of Thoracic Surgeons \\ SWAT = Surgical Access Workforce Team \\ VA-ECMO $=$ veno-arterial extracorporeal membrane oxygenation}

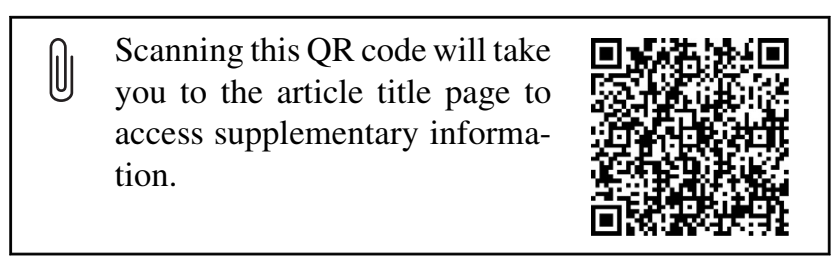

Coronavirus disease 2019 (COVID-19), caused by the severe acute respiratory syndrome coronavirus (SARSCoV)-2, has fundamentally altered the lives of people around the world, and on March 11, 2020, the World Health Organization declared COVID-19 a global pandemic. As of April 12, 2020, there were almost 2 million confirmed cases globally, with more than 500,000 cases in the United States-more than any other country. New York City, alone with more cases than any individual country, is considered to be the global epicenter of the virus at this time, with 6900 deaths. ${ }^{1}$ A major component of the international response to the pandemic has been social distancing, which has prompted travel restrictions, shelter-in-place recommendations, and closures of all nonessential businesses throughout the United States. This has drastically transformed everyday life, and although hospitals have been busier than ever dealing with a massive influx of patients with COVID-19, resource-intensive specialties, including cardiac surgery, have been nearly completely sidelined.

As the number of COVID-19 cases continues to rise, particularly in states with high numbers of cardiac surgery centers, an understanding of how the current pandemic affects the practice of cardiac surgery is important. This review highlights the effects of COVID-19 from the perspective of a busy cardiac surgery program at the epicenter of the COVID-19 pandemic, including implications for those with cardiovascular disease, disease pathophysiology in the context of common cardiac surgical procedures, and the impact on adult cardiac surgical practice during and after the pandemic.

\section{CARDIOVASCULAR MANIFESTATIONS OF COVID-19}

Although primarily a disease of the respiratory system, the cardiovascular manifestations of COVID-19 are important in the evaluation and treatment of infected patients across all disease severity classes. These include transient and chronic myocardial dysfunction, cardiogenic shock, arrythmias, and vascular thrombosis. In addition, multiple studies have identified cardiovascular disease, hypertension, and diabetes mellitus as among the most common comorbidities reported among patients with COVID-19, ${ }^{2}$ and the reported case fatality rate among patients with cardiovascular disease has been reported at $10.5 \%$, compared with only $0.9 \%$ in patients with no comorbidities. ${ }^{3}$ Cardiovascular disease appears to have profound impact on mortality when also associated with myocardial injury; patients with an elevated troponin $\mathrm{T}$ level present with greater rates of malignant arrhythmia and a mortality of more than $69 \%{ }^{4}$ Proposed mechanisms for the cardiac dysfunction observed in COVID-19 infections include viral myocarditis and myocardial dysfunction secondary to hypoxia or cytokine-mediated systemic inflammation. Decreased activity of angiotensin-converting enzyme- 2 in the heart has also been suggested as a potential mediator of cardiac dysfunction, as has been described in the SARS-CoV-1 disease. ${ }^{5}$

Of particular relevance to the cardiothoracic surgeon is the prothrombotic state that has been described with SARS-CoV-2. In analysis of 1099 patients from more than 550 hospitals across China, D-dimer was elevated in $46.4 \%$ of those tested (260/560), and this abnormality was a possible predictor of mortality. ${ }^{6}$ It has also been suggested that microvascular thrombosis and endothelial injury of the pulmonary vasculature may mediate the profound hypoxemia seen in severe cases. Guidelines for anticoagulation are emerging, and prophylactic low-molecularweight heparin is reasonable in all hospitalized patients without contraindications. ${ }^{7}$ The risk of thrombosis must be considered for all cardiovascular interventions, including mechanical circulatory support, and standard monitoring/ infusion catheters. Anticoagulation with unfractionated heparin is likely indicated for mechanical circulatory support.

\section{SYSTEM-WIDE ADAPTIONS TO THE PANDEMIC}

Extensive organizational changes have been required to increase our capacity to care for victims of COVID-19 requiring hospitalization and admission to the intensive care (ICU) but also to minimize the risk of nosocomial infection in patients without COVID-19. This involved a coordinated effort across all levels of institutional 
leadership, including the enterprise, hospital, Department of Surgery, and our own Division of Cardiac, Thoracic and Vascular Surgery (Table 1).

\section{TELEMEDICINE}

From the outset of the pandemic, a primary goal was to minimize the risk of spreading COVID-19 to patients and providers. As a result, our entire institution, across all its campuses, departments, and divisions, transitioned to a distance model of health care, using existing telemedicine platforms within the Epic electronic medical record system, as well as hospital-sanctioned, Health Insurance Portability and Accountability Act-compliant versions of publicly available platforms, such as Zoom. This has required a significant effort on the part of the hospital and university's information technology department, as well as clinicians, who had to master virtual visit software, modify clinical practice and decision making in the absence of in-person encounters, and learn to properly code and bill these visits. For patients unable to participate in telemedicine visits through these systems, publicly available and familiar platforms, such as smartphone video chat applications, or even voice calls, were a backup. Virtual visits were not appropriate for a small proportion of patients, such as those requiring physical examination or intervention, and these were seen in person.

\section{OPERATIVE VOLUME REDUCTION}

The potential for the COVID-19 pandemic to overwhelm hospital capacity has been a real concern throughout the crisis, and worldwide shortages of important resources, especially personal protective equipment (PPE) and ventilators, have been continuously reported in the media. Early on, we implemented measures to reduce the use of PPE during operations, such as limiting the number of scrubbed staff and minimizing the switching of personnel, and the medical school removed all students from clinical rotations. As the number of patients with COVID-19 admitted to our hospital rapidly increased, and facing the possibility of exhausting our supply of PPE, ventilators, continuous hemodialysis machines, and ICU beds, the difficult decision was made on March 15, 2020, to halt all elective surgery.

TABLE 1. COVID-19-driven changes in the Department of Surgery

\begin{tabular}{|c|c|c|c|}
\hline Change & Goals & Challenges & Level \\
\hline $\begin{array}{l}\text { Telemedicine } \\
\text { patient visits }\end{array}$ & $\begin{array}{l}\text { - Minimizing risk of nosocomial COVID-19 } \\
\text { infections to patients/providers } \\
\text { - Minimizing need to staff and support services }\end{array}$ & $\begin{array}{l}\text { - Inability to examine patients } \\
\text { - Difficulties obtaining outpatient studies } \\
\text { - Technical issues with Telehealth applications } \\
\text { - Lack of technical savvy among patients }\end{array}$ & $\begin{array}{l}\text { - Division } \\
\text { - Departmen } \\
\text { - Hospital } \\
\text { - Enterprise }\end{array}$ \\
\hline $\begin{array}{l}\text { Case volume } \\
\text { reduction }\end{array}$ & $\begin{array}{l}\text { - Minimizing risk of nosocomial COVID-19 } \\
\text { infections } \\
\text { - Preserving PPE, vital equipment, medications } \\
\text { - Preserving floor and ICU beds } \\
\text { - Opening space for additional ICU capacity } \\
\text { (ORICU) } \\
\text { - Making providers available to care for patients } \\
\text { with COVID-19 }\end{array}$ & $\begin{array}{l}\text { - Balancing risk of delaying operations versus risk } \\
\text { of in-hospital COVID transmission } \\
\text { - Disruption of trainees' education and surgical } \\
\text { skills } \\
\text { - Significant drop in revenue }\end{array}$ & $\begin{array}{l}\text { - Division } \\
\text { - Departmen } \\
\text { - Hospital } \\
\text { - Enterprise }\end{array}$ \\
\hline $\begin{array}{l}\text { Attending/ } \\
\text { staff/resident } \\
\text { redeployment }\end{array}$ & $\begin{array}{l}\text { - Serving as ICU attendings, ICU fellows, mid-level } \\
\text { providers, junior residents, SWAT team, perfusion, } \\
\text { and support staff in EDs, medicine floors, step- } \\
\text { down units and newly created COVID-19 ICUs }\end{array}$ & $\begin{array}{l}\text { - Adequate training and expertise in newly created } \\
\text { roles } \\
\text { - Maintaining adequate core staffing of divisional } \\
\text { and departmental services } \\
\text { - Increased risk of contracting COVID-19 } \\
\text { - Family exposure to COVID-19 } \\
\text { - Mental and emotional well-being given increased } \\
\text { levels of stress }\end{array}$ & $\begin{array}{l}\text { - Division } \\
\text { - Departmen } \\
\text { - Hospital } \\
\text { - Enterprise }\end{array}$ \\
\hline $\begin{array}{l}\text { Service and } \\
\text { on-call staffing }\end{array}$ & $\begin{array}{l}\text { - Making residents, attendings and staff available } \\
\text { for redeployment to COVID-19 units }\end{array}$ & $\begin{array}{l}\text { - Maintaining staffing levels to safely care for } \\
\text { remaining patients without COVID-19 (floors and } \\
\text { ICUs) } \\
\text { - Availability of adequate senior resident/fellow and } \\
\text { attendings to cover emergent cardiothoracic cases, } \\
\text { urgent procedures, heart/lung transplantation, and } \\
\text { organ procurement }\end{array}$ & $\begin{array}{l}\text { - Division } \\
\text { - Departmen }\end{array}$ \\
\hline
\end{tabular}

COVID-19, Coronavirus disease 2019; PPE, personal protective equipment; ICU, intensive care unit; ORICU, operating room intensive care unit; SWAT, Surgical Access Workforce Team. 
This had a dramatic effect on all surgical specialties, including cardiac surgery, and we rapidly implemented systems for identifying patients eligible for postponement, notifying them and their physicians, and monitoring postponed patients for changes in clinical status. Specifically, we developed a rubric for classifying the urgency of all scheduled operations so that the most pressing cases could be done in severely limited operating room (OR) slots. This process was often challenging, and will be discussed in greater detail later.

This sudden elimination of elective surgery severely reduced the throughput of patients in our system, so that within days, our inpatient census was at record lows. This allowed reorganization of our service staffing, making most of our personnel-including residents, fellows, faculty, mid-level providers, and administrative staff-available for redeployment. In the 4 weeks since cessation of elective cases, we have performed 12 adult cardiac operations and have deferred the remainder (see Table E1 for a detailed clinical breakdown of cases). This is a $92 \%$ reduction compared with the same period in 2019 (153 cases), and it is obvious that the financial implications of this case reduction are profound for both the hospital and our surgical practice and not likely mitigated by continued billing of telehealth visits and ICU care by redeployed physicians. These emergency cases had an overall low risk and resource use profile (Society of Thoracic Surgeons [STS] score 0.94, estimated length of stay and ICU stay 6 and 2.2 days, respectively, for cases appropriate for STS risk scoring).

\section{REDEPLOYMENT}

As our hospital became overrun by patients with COVID19, especially in "pop-up" ICUs established in ORs and other available spaces, our hospital sought to redeploy clinicians to these units. Surgeons were logical candidates for these roles, both because they had been idled by the elimination of elective surgery, and more importantly because of their broad skillset and training, including critical care expertise. This is particularly true of cardiac surgeons, whose understanding of cardiovascular and respiratory physiology makes them well-suited for care of the sickest patients with COVID-19. Our division recognized this need, and many of our faculty, trainees, extenders, and staff were among the first to volunteer for redeployment. At the hospital level, a system was developed in which clinical section heads and training program directors identify the number of clinical staff on a daily basis, including attendings and trainees, and report these figures through a webbased portal. These clinicians are then redeployed to needed areas in the hospital or on other campuses. A similar system is in place for redeployment of nurses, mid-level providers, and administrative staff. Reorganization of the cardiac surgery service allowed at least partial redeployment of 4 of 7 faculty, 9 of 15 residents and fellows, and 4 of 8 extenders. Our perfusion team, in addition to overseeing extracorporeal membrane oxygenation (ECMO), was retrained to manage continuous hemodialysis machines. While our staff has been redeployed across the institution, our clinicians have played a particularly important role in 2 newly created teams to help care for patients who test positive for COVID-19: the Surgical Access Workforce Team (SWAT) and the operating room intensive care units (ORICUs).

\section{THE SURGICAL ACCESS WORKFORCE TEAM}

The Department of Surgery organized a team of its clinicians with expertise and ability to quickly and efficiently place indwelling lines or catheters, and perform other bedside procedures, freeing up emergency department and ICU teams to focus on triaging and treating patients with COVID-19. SWAT teams each consist of a surgical attending, 1 to 2 senior residents or experienced physician assistants, and 1 to 2 junior residents, who work in 12hour shifts. Prompted by requests through the electronic medical record system, the SWAT team is dispatched with necessary supplies to place arterial lines, central lines, dialysis catheters, nasogastric tubes, Foley catheters, chest tubes, or perform other procedures. This has proven to be a remarkably efficient system, benefiting not only clinicians who can focus on other tasks, but also surgical trainees who get significant experience with these procedures.

\section{OPERATING ROOM INTENSIVE CARE UNITS}

Using projected numbers of COVID-19 cases in the metropolitan area, and taking into account Wuhan and Hubei historic data, our hospital system developed projections for numbers of inpatient and ICU beds as well as ventilators that would be needed for the surge of COVID-19 patients. A plan was developed to nearly triple the capacity of ICU beds. First, all existing ICUs were repurposed: our surgical ICU was converted into an overflow ICU for patients with COVID-19, as was the smaller of the 2 cardiothoracic ICUs; all nonsurgical ICUs (medical, neurology, and cardiology) were converted into COVID-19 units; and our main cardiothoracic ICU was designated as the "COVID-free" ICU, housing all COVID-negative medical and surgical critical care patients. Second, to increase the complement of ICU beds, the Departments of Surgery and Anesthesiology worked with hospital leadership to convert all but 2 ORs at our adult hospital into ICUs (ORICUs) (Figure 1). Each OR was reorganized to house 3 to 5 ICU beds, and each ORICU bed has an ICU ventilator, re-purposed anesthesia machine, or older transport ventilator, as well as a suction setup and vital sign monitor. In addition, significant efforts are underway to optimize protocols for split ventilation, enabling 2 patients to be connected to a single anesthesia machine ventilator. One other important technical 


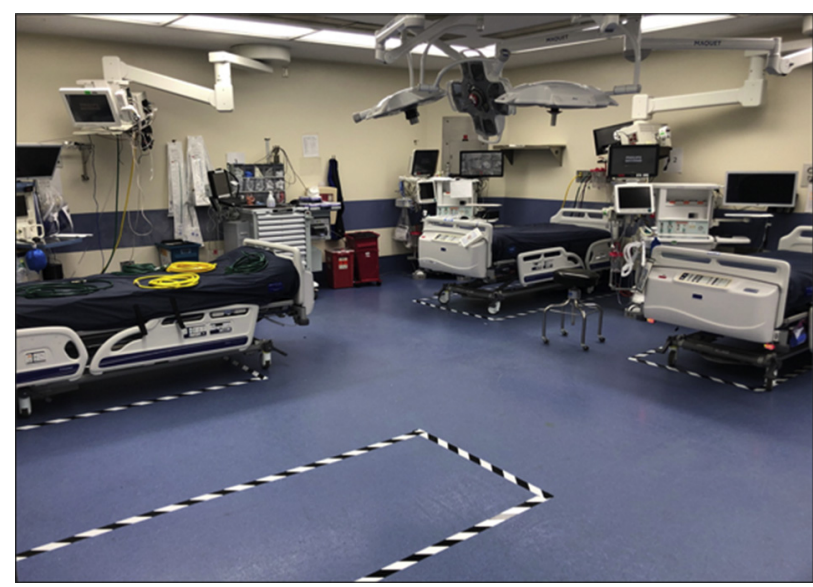

FIGURE 1. Representative photograph of an ORICU: This is an operating room that has been modified to accommodate up to 4 ventilated patients with COVID-19, each with a separate ventilator, gas lines, and other equipment.

point is that ORs, normally under positive pressure, were converted to negative pressure by an impressive effort of our construction and engineering teams.

In our hospital, ORs are organized in groups of 3 to 5 rooms around central sub-sterile cores. In the ORICU setup, each of these cores was designated as a "pod." In a pyramidal management system (Table E2), each pod is staffed with a single senior-level cardiothoracic surgical or anesthesia resident (typically postgraduate year 4-6), who serves as a critical care fellow and oversees a team of juniors, each of whom covers a single OR with 3 to 5 patients and 1 nurse. Depending on experience, these junior roles are filled by surgical or anesthesia interns or junior residents, advanced residents from other specialties, experienced surgical physician assistants, and certified registered nurse anesthetists. Each pod also has a "lead" clinician, typically an anesthesia critical care fellow or surgery attending. Finally, collections of 2 to 4 pods are each overseen by a board-certified critical care attending. Despite its makeshift nature, this model has allowed us to provide ICU care to nearly 120 additional patients with COVID-19.

\section{CHALLENGES OF REDEPLOYMENT}

It is crucially important that redeployed clinicians have adequate training and skills for their new roles. In addition to shadowing in the ICU, an extensive library of ICU principles and protocols was also developed and distributed online. Alternative roles (eg, telehealth visits or caring for patients without COVID-19) were considered for older providers, as well as those who have significant medical comorbidities or are immunosuppressed. Additional protections, such as providing alternate temporary housing, were provided by the hospital to redeployed staff members who normally live with family members at high risk of complications from COVID-19.
Finally, to promote mental and emotional well-being and provide support during these times of increased stress, our Department and Program have been organizing frequent meetings over Zoom for residents, fellows, and faculty.

Despite the elimination of elective surgery, we retained a core of our usual staff to cover continued practice activity. Most of our non-redeployed staff worked from home, although a rotation was established in which one office worker and one clinical extender were physically present in our office each day, to check mail, receive outside medical records and films, and conduct in-person patient visits. Similarly, although many of our residents and some faculty were redeployed, a core number of each were maintained to cover our clinical services, respond to emergencies, and perform urgent and emergent surgery. Specifically, we kept at least 1 surgeon available at all times who was capable of general cardiac surgery procedures, as well as more specialized areas such as aortic surgery and mechanical cardiac assistance/transplant. A rotation schedule is particularly important for programs in high infection areas, in which a percentage of providers will inevitably get sick-in our program, 2 of 10 surgical attendings and 2 of 12 integrated residents have tested positive for COVID-19.

\section{REDEFINING “URGENT" SURGERY AND ALLOCATION OF RESOURCES DURING THE PANDEMIC}

Three stages of pandemic in relation to hospital resources can be identified: (1) an "early" phase, in which resources are plentiful and there is no interruption of services; (2) a surge or "peak" phase, in which cases reach a maximum level in the community and cause maximal effect on health care services for that area; and (3) a "late" phase, with slow resolution of the surge evolving into a "steady-state" of cases (Figure 2). Each phase must be interpreted in comparison with a center's expected resource level at peak surge. If peak cases exceed hospital resources, which occurred in our center, a severe reduction in resources devoted to nonCOVID care, including elective surgery, should be expected and drastic changes to clinical practice are necessary. In contrast, if hospital resources exceed expected peak numbers throughout early, peak, and late phases, elective cases may continue, depending on urgency level and predicted resource needs.

The sudden hospital-mandated reduction of operating capacity to less than $10 \%$ of our normal required postponement of all but emergent and the most urgent procedures. Although emergency indications for surgery were least common and easiest to define (eg, patients who will die without immediate surgery, eg, acute type A aortic dissection, unstable coronary ischemia), our definition of urgent surgery, which described as many as $40 \%$ of our practice, required refinement. Our usual definition of urgent 


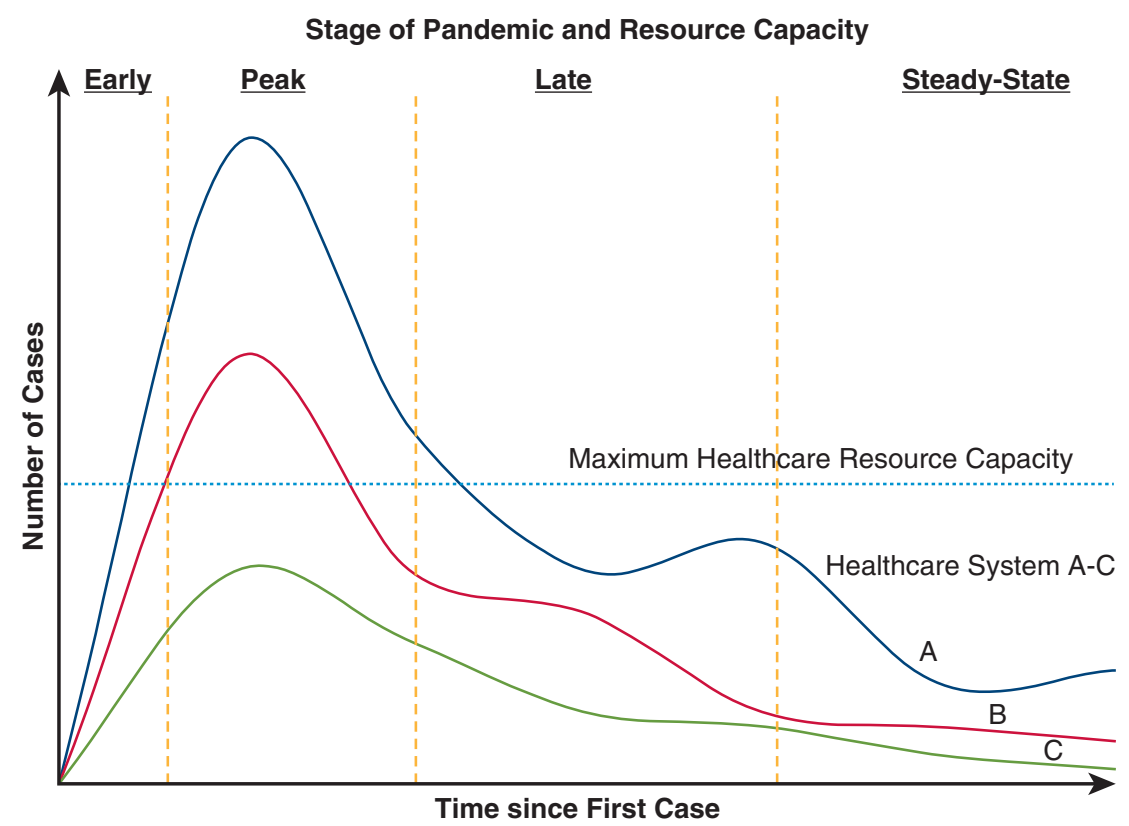

FIGURE 2. The anticipated resource use depends on the stage of the pandemic at a given health care system. Three potential scenarios can exist: system A: COVID-19 cases exceed resources, causing a complete cessation of surgery throughout the peak and affects the late phase, system B: COVID-19 cases cause major disruption only in the peak phase, and system C: COVID-19 cases stay below maximum resource capacity, allowing elective cases to proceed. Note there is a predicted bump in cases within the late phase as distancing measures are relaxed.

surgery-procedures that must be done not immediately, but within the current hospitalization-assumed normal hospital and OR capacity, which no longer applied, so we developed our own classification system based on best estimates of how long each patient could wait before becoming emergent: 1 to 2 weeks, 3 to 4 weeks, or greater than 4 weeks (Table 2). Such a classification is very helpful in minimizing the adverse consequences of postponement

TABLE 2. Timing of cardiac surgery intervention depending on case type and urgency category

\begin{tabular}{|c|c|c|c|c|}
\hline Category & Emergent & 1: Urgent & 2: Semi-urgent & 3: Elective \\
\hline Timing & Immediate entry- $72 \mathrm{~h}$ & $1-2 \mathrm{wk}$ & $3-4 \mathrm{wk}$ & $>1 \mathrm{mo}$ \\
\hline $\begin{array}{l}\text { CAD (not amenable } \\
\text { to PCI) }\end{array}$ & $\begin{array}{l}\text { - Critical CAD/LM } \pm \\
\text { shock/IABP/pressors }\end{array}$ & $\begin{array}{l}\text { - LM, ACS or w/3VD with } \\
\text { high-risk anatomy }\end{array}$ & - 3VD w/increasing Sx & - Stable CAD \\
\hline $\begin{array}{l}\text { AV (not amenable } \\
\text { to TAVR) }\end{array}$ & $\begin{array}{l}\text { - Severe AI w/shock } \\
\text { - Severe AS w/shock }\end{array}$ & $\begin{array}{l}\text { - Severe AI/AS w/NYHA IV HF, } \\
\text { syncope } \\
\text { - BHV SVD w/NYHA IV HF }\end{array}$ & $\begin{array}{l}\text { - Critical/severe AS w/high risk } \\
\text { features or progressive Sx } \\
\text { - Progressive severe AI with } \\
\text { progressive Sx }\end{array}$ & $\begin{array}{l}\text { - Stable severe } \\
\text { AI/AS }\end{array}$ \\
\hline $\begin{array}{l}\text { MV disease (not } \\
\text { amenable to MC) }\end{array}$ & - Acute MR w/shock & $\begin{array}{l}\text { - Acute MR with NYHA IV HF } \\
\text { - BHV SVD w/NYHA IV HF }\end{array}$ & $\begin{array}{l}\text { - Severe MR w/drop in EF, recurrent } \\
\text { HF } \\
\text { - MS with NYHA III-IV HF }\end{array}$ & $\begin{array}{l}\text { - Stable severe } \\
\text { MR/MS }\end{array}$ \\
\hline $\begin{array}{l}\text { Tricuspid valve } \\
\text { disease }\end{array}$ & - N/A & - N/A & - NYHA IV Sx & - Stable Severe TR \\
\hline Aortic surgery/other & $\begin{array}{l}\text { - Type A dissection } \\
\text { - PTE w/massive clot }\end{array}$ & $\begin{array}{l}\text { - Giant TAA/PSA w/Sx or rapid } \\
\text { expansion }\end{array}$ & - TAA $>6-7 \mathrm{~cm}$ & $\begin{array}{l}\text { - Stable TAA } \\
\text { - PTE for CTEPH }\end{array}$ \\
\hline Transplant & - N/A & - Inpatient + status $1-2$ & - N/A & - Stable outpatient \\
\hline
\end{tabular}

$C A D$, Coronary artery disease; $P C I$, percutaneous coronary intervention; $L M$, left main; IABP, intra-aortic balloon pump; $A C S$, acute coronary syndrome; $3 V D$, triple-vessel disease; $S x$, symptoms; $A V$, aortic valve; $T A V R$, transcatheter aortic valve replacement; $A I$, aortic insufficiency; $A S$, aortic stenosis; $N Y H A$, New York Heart Association; $H F$, heart failure; $B H V$, bioprosthetic heart valve; $S V D$, structural valve degeneration; $M V$, mitral valve; $M C$, Mitraclip; $M R$, mitral regurgitation; $E F$, ejection fraction; $M S$, mitral stenosis; $N / A$, not available; TR, tricuspid regurgitation; PTE, pulmonary thromboendarterectomy; TAA,thoracic aortic aneurysm; PSA, pseudoaneurysm; CTEPH, chronic thromboembolic pulmonary hypertension. 
by prioritizing patients at highest risk of decompensation, and can be modified as resource limitations change.

For patients classified as elective (ie, can wait greater than 4 weeks), postponement for as long as possible is reasonable not only as a resource-preserving measure but also to avoid the risk of perioperative COVID-19 infection. Given the poor prognosis of COVID-19 patients with acute coronary syndrome, ${ }^{8}$ COVID-19 infection during cardiac surgery may be associated with high mortality, regardless of the calculated STS score. Data from China support this hypothesis: in 34 patients undergoing elective noncardiac surgery in Wuhan China during the early period of infection, all patients became infected with COVID-19, 44\% required ICU admission, and mortality was $20.5 \%$. ${ }^{9}$ In our experience of 12 cases, 2 patients tested positive for COVID-19 postoperatively (Table E1): one patient with unknown preoperative infection and one patient with a negative preoperative test followed by clinical symptoms and seroconversion postoperatively.

Even with this prioritization scheme, severely limited resources may not be able to accommodate all deserving patients. The first option in these situations is draw upon the full armamentarium of treatment options, including nonsurgical percutaneous options, even if they may normally be considered less definitive or durable. For example, severe symptomatic aortic stenosis or prosthetic aortic valve insufficiency (even in low-risk patients) could be treated by transcatheter aortic valve replacement, avoiding a long hospital stay. Other examples include percutaneous coronary intervention for severe coronary disease and MitraClip (Abbott, Chicago, Ill) for acutely decompensated degenerative or functional mitral regurgitation.

For patients deemed urgent after adjudication by individual surgical divisions, and without percutaneous alternatives, we applied a further level of selection, in which the predicted resource intensity of a specific operation was considered in the filling of very limited available OR slots. Factors considered in the estimation of this "resource intensity," in addition to OR space and personnel, included the anticipated need for limited resources such as PPE, ventilators, dialysis machines, and blood products, as well as the expected consumption of postoperative resources, such as ICU beds. This system allowed flexibility in selection of appropriate cases to be performed, according to which specific resources were in greater or lesser abundance at a given time. So that all available information could be considered, ultimate decisions about scheduling of these urgent operations were made at the highest levels of hospital administration, with input from the Chairman of Surgery.

Our system has thus far allowed us to manage our urgent caseload, but this may not be the case, as our resources are increasingly strained by the unrelenting pandemic. For urgent and even emergent patients at the high end of the risk spectrum, or for whom the expected benefit of surgery is marginal, palliative care may need to play a more prominent role, since prolonged ICU and hospital stays cannot be justified. In the end, the anticipated benefit and risk, as well as resource intensity, of a proposed procedure must be balanced against available resources at a given time, and this complex relationship is represented in Figure 3, A, with sample cases in Figures $3, B$ and $C$.

Regardless of the specific definitions of urgent and elective surgery during a period of decreased access, it is important for surgeons to closely monitor patients who have been postponed. These patients are at risk for progression of their disease while they wait, especially since they don't have normal access to their cardiologists and primary care physicians, or even pharmacies. We have instituted a system in which all patients previously scheduled for surgery, or with new appointments for surgical consultation, are contacted regularly (at least once per week) by their surgeon or a physician extender. In at least 2 cases, this system has identified a patient who was initially deemed stable for postponement but decompensated clinically at home, requiring urgent surgery.

\section{CONSIDERATIONS IN PATIENTS REQUIRING CARDIAC SURGERY DURING THE PANDEMIC}

Pre-, intra-, and postprocedural care for patients undergoing cardiothoracic surgery amid the COVID-19 pandemic should differ from usual routines. These are detailed in Table 3, with primary principles including robust screening of patients for suspected infection, streamlining of preoperative processes, intraoperative protocols to maintain infection control, and expedited postoperative recovery, including virtual follow-up. Specific recommendations for the most commonly performed procedures follow.

\section{Coronary Artery Bypass Grafting and Valve Operations}

Patients with stable coronary disease are at relatively low risk of mortality and should be postponed - a proposal supported by the recent ISCHEMIA trial. ${ }^{10}$ However, patients presenting with acute coronary syndrome and severe left main disease or triple-vessel disease with high syntax score, especially if not amenable to percutaneous coronary intervention, should be considered for urgent surgery. Mechanical complications of coronary ischemia, such as ventricular septal defect or acute papillary muscle rupture, can be considered for operative therapy on a case-by-case basis.

A similar strategy should be employed for valve operations. Patients with asymptomatic severe aortic stenosis should be postponed due to low annual risk of sudden cardiac death, ${ }^{11}$ and even symptomatic severe aortic stenosis patients should be stratified based on duration and severity of symptoms. Left-sided endocarditis with hemodynamic compromise or very large vegetations should be 

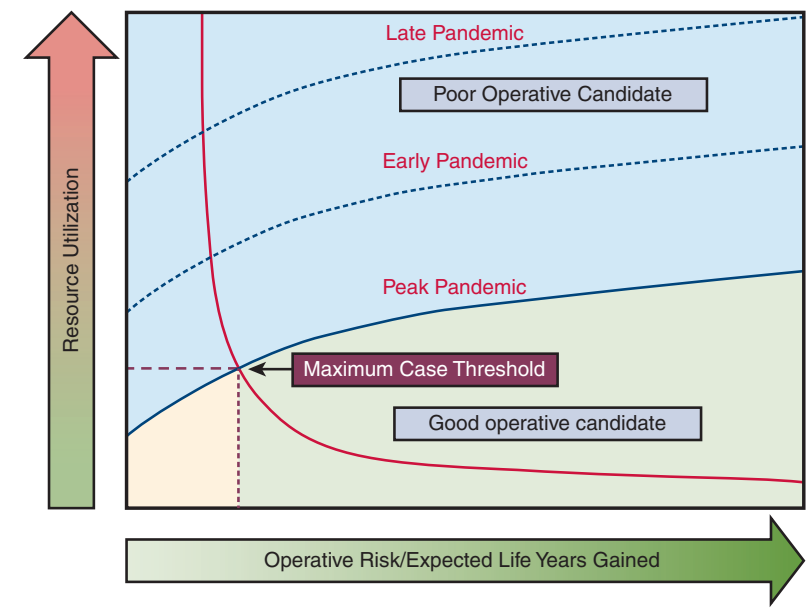

Legend Resources available per
pandemic level

_ Resource utilization for proposed case

$\square$ Good operative candidate

$\square$ Questionable candidate

A

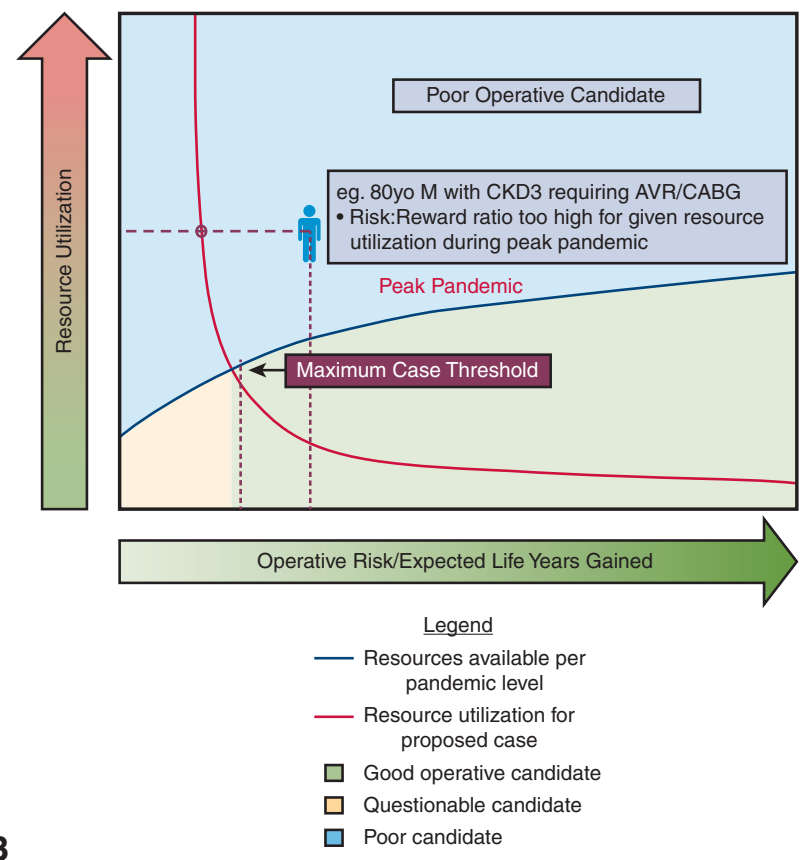

B

$\square$ Poor candidate

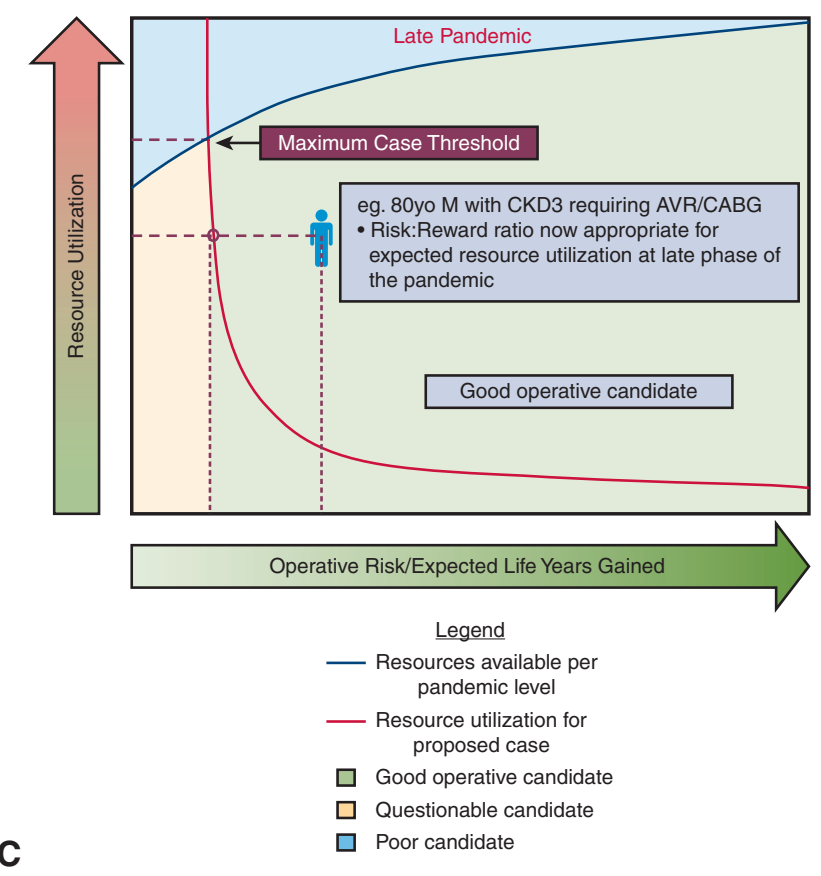

FIGURE 3. A, Decision-making strategy for surgical planning based on pandemic phase, given operative risks and expected life years gained, resource use, and resource limitations. In this figure, 3 phases of pandemic can be plotted with resource expenditure on the vertical axis (blue line: resources available; orange line: resource use), and operative risk and expected survival benefit on the horizontal axis. The intersection of the orange and blue resource lines represents the maximum case threshold for a health care system at a given time. This graph thus incorporates the changing level of resources at different stages of the pandemic, as illustrated by a sample case of an 80-year-old patient with CKD requiring AVR/CABG. In B, during the peak of the pandemic, this operation is not justified; in $\mathrm{C}$, during later stages of the pandemic, this operation is justified. $C K D$, Chronic kidney disease; $A V R$, aortic valve replacement; $C A B G$, coronary artery bypass grafting. 
TABLE 3. Pre-, intra-, and postoperative considerations for caring for cardiac surgery patients in the COVID-19 era

\begin{tabular}{|c|c|c|}
\hline Preoperative & Intraoperative & Postoperative \\
\hline $\begin{array}{l}\text { - Routine COVID-19 infection testing } 24-48 \mathrm{~h} \\
\text { before } \\
\text { - Travel and potential exposure history } \\
\text { - Close CXR review } \\
\text { - Forego nonessential testing when possible } \\
\text { - Consider use of older testing data when } \\
\text { possible } \\
\text { - Preoperative care via telehealth } \\
\text { - Patients don surgical mask upon hospital } \\
\text { arrival } \\
\text { - Early intubation preoperatively for suspected } \\
\text { COVID-19 + patients in respiratory distress } \\
\text { - Deferring case if COVID+ }\end{array}$ & $\begin{array}{l}\text { - Non-COVID operating rooms } \\
\text { - Conversion of ORs to negative-pressure } \\
\text { - Airborne precautions and PPE worn by all } \\
\text { providers } \\
\text { - Nonessential staff not in room } \\
\text { - Attending level surgical staff only } \\
\text { - Video laryngoscopy for intubation } \\
\text { - Minimize staff turnover within room } \\
\text { - Forego TEE if appropriate } \\
\text { - Avoid pleural entry and lung injury } \\
\text { - Avoid procedures with } \mathrm{CO}_{2} \text { insufflation }\end{array}$ & $\begin{array}{l}\text { - } \text { Clean recovery area } \\
\text { - Suspect COVID-19 infection if prolonged } \\
\text { respiratory failure } \\
\text { - Minimize risks of renal failure and prolonged } \\
\text { respiratory failure } \\
\text { - Enhanced recovery protocol if appropriate: } \\
\text { early extubation, mobilization, and removal of } \\
\text { chest tubes and pacing wires } \\
\text { - Patients don surgical mask immediately after } \\
\text { extubation } \\
\text { - Early coordination with family for at-home } \\
\text { postoperative recovery } \\
\text { - Early discharge when medically stable } \\
\text { - Close and frequent virtual follow-up after } \\
\text { discharge } \\
\text { - Repeat COVID-19 if clinical symptoms } \\
\text { develop }\end{array}$ \\
\hline
\end{tabular}

COVID-19, Coronavirus disease 2019; CXR, chest X-ray, OR, operating room; PPE, personal protection equipment, TEE, transesophageal echocardiography.

prioritized over cases that can be managed medically until resources improve. Most mitral valve patients can also be delayed but should be aggressively managed medically and monitored closely for signs of decompensated heart failure.

\section{Aortic Surgery}

There is little argument about the need for emergent surgery for acute type A aortic dissection or ruptured aortic aneurysm, unless the other factors such as malperfusion, prolonged shock, or older age predict a very poor prognosis. In contrast, the decision to operate on high-risk thoracic aortic aneurysms, such as symptomatic, rapidly-growing, or giant aneurysms $(>7 \mathrm{~cm})$ as well as (saccular) pseudoaneurysms, is much more complicated and may be considered for urgent surgery depending on the risk of aneurysm-related death and the availability of resources. Asymptomatic patients with smaller aneurysms can have surgery delayed for 2 to 3 months. Another consideration is to tailor the repair to a more conservative approach versus a more extensive aortic resection, ie, a hemiarch and ascending replacement compared with a comprehensive aortic root and total arch replacement. Medical management should be the choice for uncomplicated acute type B aortic dissection with endovascular therapy considered for complicated cases.

\section{Heart Transplantation and Mechanical Circulatory Support}

There are numerous factors that make the normal operation of an orthotopic heart transplantation program impractical or impossible, particularly in regions with high COVID infection rates. ${ }^{12}$ Newly transplanted patients requiring immunosuppression are presumably at high risk for COVID infection, particularly in hospitals in highly infected areas. A recent report from China describes 2 recipients of an orthotopic heart transplantation who presented with COVID infection, ${ }^{12}$ one with minimal symptoms and normal recovery, the other requiring hospital admission, antiviral treatment, and temporary discontinuation of immunosuppression. At our institution, newly transplanted patients have been moved to a single non-COVID ICU in an effort to minimize infection risk. Only patients who are status 1 or 2 have remained active on the waiting list, due their increased short-term risk of mortality, and only documented COVID-negative donor offers are accepted.

The Extracorporeal Life Support Organization continues to recommend veno-arterial extra-corporeal membrane

TABLE 4. Columbia University Irving Medical Center's criteria for VA-ECMO use in the COVID-19 era

\begin{tabular}{ll}
\hline $\begin{array}{c}\text { Criteria for consideration } \\
\text { of VA-ECMO }\end{array}$ & \multicolumn{1}{c}{ Contraindication } \\
\hline SCAI criteria C or D & SCAI criteria E (extremis) \\
\hline SAVE score $\geq 1$ & Age $>60$ y \\
\hline Minimal comorbidities & Severe peripheral vascular disease \\
& Septic shock as primary etiology \\
& Acute stroke \\
& Contraindication to anticoagulation \\
& End-stage renal failure \\
\hline
\end{tabular}

VA-ECMO, Veno-arterial extracorporeal membrane oxygenation; SCAI, Society for Cardiovascular Angiography and Interventions; SAVE, Survival After Veno-Arterial ECMO. 
oxygenation (VA-ECMO) for standard indications; however, exclusions for patients with COVID-19 are left to the discretion of local health care organizations, based on health care work risk and resource constraints. ${ }^{13}$ At our center, VA-ECMO is still available to patients with cardiovascular collapse, with priority given to younger patients and health care workers with fewer comorbidities, but only after discussion with our multidisciplinary heart failure team (Table 4). Currently, patients are considered for VAECMO if meeting Society for Cardiovascular Angiography and Interventions criteria for Stage C or D cardiogenic shock, and with Survival After Veno-arterial ECMO score $\geq 1$. Patients in extremis (Society for Cardiovascular Angiography and Interventions stage E), age older than 60 years, or with septic shock, severe peripheral vascular disease, chronic lung or liver disease, and end-stage renal disease are not considered. Anecdotally, the cases of COVIDinduced myocardial dysfunction at our institution have often resolved concurrently with the inflammatory state, thus supporting a restrictive approach. Finally, we are not offering ECMO during cardiopulmonary resuscitation to confirmed or suspected patients with COVID-19 and have significantly limited this in patients without COVID-19 as well.

Left ventricular assist device (LVAD) implantation presents several challenges in the setting of COVID-19. These patients often suffer a profound inflammatory response, which would be exacerbated by COVID-19 infection. Specifically, patients with LVADs develop increased interleukin- 6 cytokine levels within the first 6 weeks of implantation, ${ }^{14,15}$ which are thought to correlate with COVID19 severity. ${ }^{16}$ Furthermore, because of the now described COVID-19-associated coagulopathy, ${ }^{7}$ infected patients with LVADs would be difficult to anticoagulate, with an increased risk of thrombotic complications. Finally, should an patient with an LVAD develop acute respiratory distress syndrome, it would be challenging to perform prone ventilation, given the risk of outflow graft and driveline compression and as well as decreased cardiac output from impaired venous return. ${ }^{17,18}$ In summary, the profound physiologic burden of this operation, coupled with its resource intensity, make it prudent to delay as long as possible during the COVID-19 pandemic.

\section{TRANSITION OF CARDIAC SURGICAL PRACTICE DURING THE RECOVERY PHASE}

Although the incidence of COVID-19 may decline, the strain on hospital systems is likely to continue for a prolonged period of time. With this in mind, it is likely that the hardest-hit hospitals will be unable to resume elective procedures in the near future and not immediately at previous levels. As the total number of hospitalized coronavirus patients declines, it is likely that a gradual return of cardiothoracic surgical volume will occur, with the sickest patients prioritized for earlier operation. As operative volume slowly ramps up, there is likely to be a significant backlog of patients whose care was delayed due to the COVID-19 epidemic. For this reason, the continued management of the "postponement list," including communication with patients and their physicians, is imperative so that patients ready for surgery can be scheduled when capacity returns. Another strategy we are employing to prepare for this phase is to encourage our referring physicians to talk to us about patients they are not referring due to the crisis so that we can schedule virtual visits and establish a "bullpen" of patients who will need only a brief visit or preoperative testing to be ready for surgery. To accommodate all such patients, it may be necessary to schedule cases on weekends during this recovery phase.

Advanced presentations of common cardiac conditions will also arise because of care that was delayed due to limited resources or the reluctance of patients to seek care during the height of the pandemic. Late complications of myocardial infarction, such as heart failure or postinfarct ventricular septal defect, may be seen more frequently. Patients with valve disease may present with symptoms of advanced or decompensated heart failure, and perhaps decreased ventricular function. The reported incidence of aortic dissection presenting for acute care has anecdotally dropped, and perhaps more chronic dissections will emerge as a consequence. There is evidence that patients may be seeking medical care less frequently: in a poll by @ angioplasty.org, more than $50 \%$ of respondents reported a $40 \%$ to $60 \%$ reduction in admissions for myocardial infarction. Ultimately, this delay in care may increase the chronic cardiac disease burden and may result in a need for more intensive follow-up care and repeat hospitalization, adding stress to the recovering hospital system.

\section{CONCLUSIONS}

As we continue to confront the COVID-19 pandemic, it is clear that multidisciplinary collaboration, willingness and flexibility to alter institutional practices, and the ability to maintain core surgical skills, while using them in the care of critically ill patients, will be required from cardiac surgical programs. The impact on each individual program will depend on the balance between the intensity of COVID19 infection and resource capacity, and after the surge and peak of cases has been met, a return to normalcy is inevitable. Despite the unprecedented disruption of our practices and lives that this pandemic has produced, we will undoubtedly emerge from the experience stronger and more efficient as a specialty.

\section{Conflict of Interest Statement}

The authors reported no conflicts of interest.

The Journal policy requires editors and reviewers to disclose conflicts of interest and to decline handling or 
reviewing manuscripts for which they may have a conflict of interest. The editors and reviewers of this article have no conflicts of interest.

We acknowledge our staff that has helped us through this crisis, including our residents, division administrators, nurses, physician assistants, nurse practitioners, and other support staff.

\section{References}

1. Johns Hopkins University Coronavirus Resource Center. COVID-19 Dashboard by the Center for Systems Science and Engineering at Johns Hopkins University. 2020. Available at: https://coronavirus.jhu.edu/map.html. Accessed April 6, 2020.

2. Yang J, Zheng Y, Gou X, Pu K, Chen Z, Guo Q, et al. Prevalence of comorbidities in the novel Wuhan coronavirus (COVID-19) infection: a systematic review and meta-analysis. Int J Infect Dis. 2020;20:S1201-971.

3. Wu Z, McGoogan JM. Characteristics of and important lessons from the coronavirus disease 2019 (COVID-19) outbreak in China: summary of a report of 72314 cases from the Chinese center for disease control and prevention. J Am Med Assoc. 2020;323:1239-42.

4. Bonow RO, Fonarow GC, O'Gara PT, Yancy CW. Association of coronavirus disease 2019 (COVID-19) with myocardial injury and mortality. JAMA Cardiol. March 27, 2020 [Epub ahead of print].

5. Guo J, Huang Z, Lin L, Lv J. Coronavirus disease 2019 (COVID-19) and cardiovascular disease: a viewpoint on the potential influence of angiotensin-converting enzyme inhibitors/angiotensin receptor blockers on onset and severity of severe acute respiratory syndrome coronavirus 2 infection. J Am Heart Assoc. 2020;9; e016219.

6. Chen T, Wu D, Chen H, Yan W, Yang D, Chen G, et al. Clinical characteristics of 113 deceased patients with coronavirus disease 2019: retrospective study. $\mathrm{Br} \mathrm{Med}$ J. 2020;368:m1091.

7. Thachil J, Tang N, Gando S, Falanga A, Cattaneo M, Levi M, et al. ISTH interim guidance on recognition and management of coagulopathy in COVID-19. J Thromb Haemost. 2020;18:1023-6.

8. Zheng YY, Ma YT, Zhang JY, Xie X. COVID-19 and the cardiovascular system. Nat Rev Cardiol. 2020;17:259-60.
9. Lei S, Jiang F, Su W, Chen C, Chen J, Mei W, et al. Clinical characteristics and outcomes of patients undergoing surgeries during the incubation period of COVID-19 infection. EClinicalMedicine. 2020;21: 100331.

10. Spertus JA, Jones PG, Maron DJ, O'Brien SM, Reyonolds HR, Rosenberg Y, et al Health-status outcomes with invasive or conservative care in coronary disease. $N$ Eng J Med. 2020;382:1408-19.

11. Tribouilloy C, Rusinaru D, Bohbot Y, Marechaux S, Vanoverschelde JL, Enriquez-Sarano M. How should very severe aortic stenosis be defined in asymptomatic individuals? J Am Heart Assoc. 2019;8:e011724.

12. Li F, Cai J, Dong N. First cases of COVID-19 in heart transplantation from China J Heart Lung Transplant. 2020;132:1620-9.

13. Extracorporeal Life Support Organization. ELSO Guidance Document: ECMO for COVID-19 Patients with Severe Cardiopulmonary Failure. ELSO.org. 2020. Available at: https://www.elso.org/Portals/0/Files/pdf/ECMO $\% 20$ for $\% 20$ COVID \%2019\%20Guidance\%20Document.Final\%2003.24.2020.pdf. Accessed April 7, 2020.

14. Corry DC, DeLucia A III, Zhu H, Radcliffe RR, Brevetti GR, El-Khatib H, et al Time course of cytokine release and complement activation after implantation of the HeartMate left ventricular assist device. Am Soc Artif Organs. 1992;44: M347-51.

15. Masai T, Sawa Y, Ohtake S, Nishida T, Nishimura M, Fukushima N, et al. Hepatic dysfunction after left ventricular mechanical assist in patients with end-stage heart failure: role of inflammatory response and hepatic microcirculation. Ann Thorac Surg. 2020;73:549-55.

16. Russell B, Moss C, George G, Santaolalla A, Cope A, Papa S, et al. Associations between immune-suppressive and stimulating drugs and novel COVID-19-a systematic review of current evidence. Ecancermedicalscience. 2020;14:1022.

17. Kollmar JP, Colquhoun DA, Huffmyer JL. Anesthetic challenges for posterior spine surgery in a patient with left ventricular assist device: a case report. $A A$ Case Rep. 2017;9:77-80.

18. Chau VQ, Oliveros E, Mahmood K, Singhvi A, Lala A, Moss N, et al. The imperfect cytokine storm: severe COVID-19 with ARDS in patient on durable LVAD support. JACC Case Rep. April 8, 2020 [Epub ahead of print].

Key Words: cardiac surgery, COVID-19, pandemic, New York, reorganization 
TABLE E1. Surgical case description following elective case moratorium

\begin{tabular}{|c|c|}
\hline Case & Case description \\
\hline CABG & 57-yo M w/DM, previous STEMI, presented with AMI, reduced EF, complex 3VD. \\
\hline CABG & $\begin{array}{l}\text { 54-yo M/DM, PCI, unstable angina, distal LM, low EF. Postoperative respiratory failure, AKI req CVVHD, diffuse } \\
\text { emboli + CVA. New COVID+ postoperatively. }\end{array}$ \\
\hline Reop ARR/hemiarch & 53-yo M w/previous AVR, $4.7 \mathrm{~cm}$ root +7 -cm ascending TAA. LHC + surgery same day in hybrid room. \\
\hline MVR & 66-yo F w/chronic MR presenting NYHA class IV Sx from home despite OMT. \\
\hline MVR + septal myectomy & 60-yo F w/HOCM, HFpEF w/acute NYHA Class IV Sx and mean LVOT gradient $63 \mathrm{~mm} \mathrm{Hg.}$ \\
\hline AVR/MVR & 58-yo M w/critical AS (MG 69 mm Hg), severe MR with NYHA class IV Sx. \\
\hline LA mass resection & 37-yo F w/recent CVA, LA mass c/w myxoma. Preoperative MRI showed new emboli. \\
\hline OHT & 31-yo F w/NICM due to viral myocarditis (EF 15\%). COVID-. \\
\hline PTE & 63-yo F w/submassive PE s/p VA-ECMO assisted suction thrombectomy, ECMO decannulation. \\
\hline $\begin{array}{l}\text { VA-ECMO conversion } \\
\text { to VV-ECMO }\end{array}$ & 62-yo M w/CTEPH s/p PTE with mixed cardiogenic and respiratory shock \\
\hline VA-ECMO decannulation & 36-yo F w/DM w/bacterial PNA and PEA arrest, COVID-. \\
\hline LVAD & 30-yo F with congenital heart surgery, new myocarditis and heart failure, COVID- preop. New COVID+ postoperatively. \\
\hline \multicolumn{2}{|c|}{$\begin{array}{l}C A B G \text {, Coronary artery bypass grafting; } y o \text {, year-old; } M \text {, male; } D M \text {, diabetes mellitus; } S T E M I \text {, ST-segment elevation myocardial infarction; } A M I \text {, acute myocardial infarction; } E F \text {, } \\
\text { ejection fraction; } 3 V D \text {, triple vessel disease; } P C I \text {, percutaneous coronary intervention; } L M \text {, left main; } A K I \text {, acute kidney injury; } C V V H D \text {, continuous veno-venous hemodialysis; } \\
C V A \text {, cerebrovascular accident; } A R R \text {, aortic root replacement; } A V R \text {, aortic valve replacement; } T A A \text {, thoracic aortic aneurysm; } L H C \text {, left heart catheterization; } M V R \text {, mitral valve } \\
\text { replacement; } F \text {, female; } M R \text {, mitral regurgitation; } N Y H A \text {, New York Heart Association; } S x \text {, symptoms; } O M T \text {, optimal medical therapy; } H C O M \text {, hypertrophic cardiomyopathy; } \\
H F p E F \text {, heart failure with preserved ejection fraction; } L V O T \text {, left ventricular outflow tract; } A S \text {, aortic stenosis; } L A \text {, left atrial; } M R I \text {, magnetic resonance imaging; } N I C M \text {, non- } \\
\text { ischemic cardiomyopathy; PTE, pulmonary thromboendarterectomy; } P E \text {, pulmonary embolus; } V A \text {, veno-arterial; } E C M O \text {, extracorporeal membrane oxygenation; } V V \text {, veno- } \\
\text { venous; } C T E P H \text {, chronic thromboembolic pulmonary hypertension; } P N A \text {, pneumonia; } P E A \text {, pulseless electrical activity. }\end{array}$} \\
\hline
\end{tabular}


TABLE E2. ORICU organizational structure

\begin{tabular}{|c|c|c|c|c|c|c|}
\hline Floor & Pod & OR & Junior & Senior & Lead & Oversight \\
\hline \multirow[t]{13}{*}{ One floor } & A & 1 & Intern or & \multirow{4}{*}{$\begin{array}{l}\mathrm{CT} \text { surgery or anesthesia senior } \\
\text { resident or fellow }\end{array}$} & \multirow{4}{*}{$\begin{array}{l}+/- \text { Anesthesia critical care fellow } \\
\text { or surgery attending }\end{array}$} & \multirow{13}{*}{$\begin{array}{l}\text { Board-certified critical } \\
\text { care attending }\end{array}$} \\
\hline & & 2 & PGY 2-4 or & & & \\
\hline & & 3 & CRNA or & & & \\
\hline & & 4 & $\mathrm{PA}$ & & & \\
\hline & B & 5 & Intern or & & & \\
\hline & & 6 & PGY 2-4 or & \multirow{3}{*}{$\begin{array}{l}\text { CT surgery or anesthesia senior } \\
\text { resident or fellow }\end{array}$} & & \\
\hline & & 7 & CRNA or & & \multirow{2}{*}{$\begin{array}{l}+/ \text { - Anesthesia critical care fellow } \\
\text { or surgery attending }\end{array}$} & \\
\hline & & 8 & $\mathrm{PA}$ & & & \\
\hline & $\mathrm{C}$ & 9 & Intern or & & & \\
\hline & & 10 & PGY 2-4 or & & & \\
\hline & & 11 & CRNA or & & & \\
\hline & & 12 & $\mathrm{PA}$ & \multirow{2}{*}{$\begin{array}{l}\text { CT surgery or anesthesia senior } \\
\text { resident or fellow }\end{array}$} & \multirow{2}{*}{$\begin{array}{l}+/ \text { - Anesthesia critical care fellow } \\
\text { or surgery attending }\end{array}$} & \\
\hline & & 13 & as above & & & \\
\hline
\end{tabular}

$O R$, Operating room; $P G Y$, postgraduate year; $C R N A$, certified registered nurse anesthetist; $P A$, physician's assistant; $C T$, cardiothoracic. 